\title{
Leveraging community engagement capacity to address COVID-19 disparities among Pacific Islander and Latinx Communities in Arkansas
}

\section{Implementation, Policy and Community Engagement Special Communication}

Cite this article: McElfish PA, Cleek $A B$, Willis DE, Purvis RS, and James LP. Leveraging community engagement capacity to address COVID-19 disparities among Pacific Islander and Latinx Communities in Arkansas. Journal of Clinical and Translational Science 5: e81, 1-4. doi: $10.1017 /$ cts.2020.562

Received: 29 September 2020 Revised: 24 November 2020 Accepted: 25 November 2020

\section{Keywords:}

COVID-19; disparities; community engagement; Pacific Islanders; Latinx

\section{Address for correspondence:}

P. A. McElfish, PhD, MBA, College of Medicine, University of Arkansas for Medical Sciences Northwest, Fayetteville, AR 72703, USA. Email: PAMcelfish@uams.edu
(C) The Association for Clinical and Translational Science 2021. This is an Open Access article, distributed under the terms of the Creative Commons Attribution licence (http:// creativecommons.org/licenses/by/4.0/), which permits unrestricted re-use, distribution, and reproduction in any medium, provided the original work is properly cited.

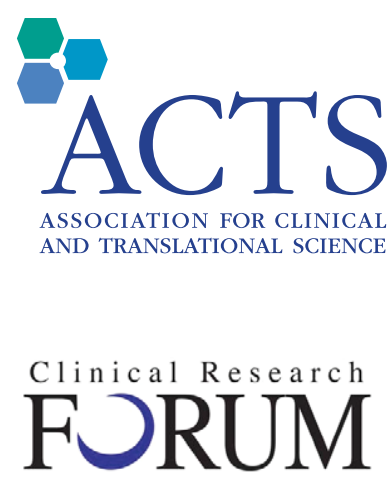

Analysis. Advocacy. Action.

\section{Pearl A. McElfish ${ }^{1}\left(\mathbb{D}\right.$, Anna B. Cleek ${ }^{1}$, Don E. Willis², Rachel S. Purvis ${ }^{2}$ and}

Laura P. James ${ }^{3}$

${ }^{1}$ Internal Medicine, College of Medicine, University of Arkansas for Medical Sciences Northwest, Fayetteville, AR, USA; ${ }^{2}$ Office of Community Health and Research, University of Arkansas for Medical Sciences Northwest, Fayetteville, AR, USA and ${ }^{3}$ Department of Pediatrics, University of Arkansas for Medical Sciences, Little Rock, AR, USA

\section{Abstract}

Northwest Arkansas, particularly Benton and Washington counties, is one of the highest COVID-19 hot spots in the United States (US), with more than half of all reported cases in this area identifying as Latinx or Pacific Islander, even though these communities account for less than $20 \%$ of the overall population. The University of Arkansas for Medical Sciences (UAMS) leveraged their existing relationship with 18 key community partners. Partners collaboratively developed a COVID-19 Response Strategy to ensure coordinated effort for Latinx and Pacific Islander communities with four interrelated strategies: health education, testing, contact tracing, and supported quarantine/case management.

\section{Introduction}

The Centers for Disease Control and Prevention (CDC) documented the first United States (US) laboratory-confirmed case of COVID-19 on January 22, 2020 [1]. By June 2020, the US had over 3 million confirmed cases of COVID-19, and low-income neighborhoods showed high positivity rates for COVID-19 testing (30\%-35\%), compared to nationwide rates of $8.8 \%$ [2]. COVID19 infections, hospitalizations, and deaths are disparate across racial and ethnic groups in the US, disproportionately impacting minority communities [3]. These disparities are magnified in certain areas of the US. For example, majority-minority counties in the US report infection rates $300 \%$ higher than that of White-majority counties, and death rates nearly $600 \%$ higher [4].

In June 2020, Northwest Arkansas, and in particular Benton and Washington counties, was one of the highest COVID-19 hot spots in the US. The racial and ethnic disparities of COVID-19 cases are so stark that the CDC conducted an in-depth community-level investigation in June and July 2020. The National Institutes of Health (NIH) followed suit in early August 2020. According to the CDC's July 2020 report, $45 \%$ of all adult cases in Northwest Arkansas identified as Hispanic/Latinx, and 19\% were Pacific Islander [5]. These communities only account for $17 \%$ and $2.4 \%$, respectively, of the two-county population. Latinx and Pacific Islander community members encounter many socioeconomic challenges, including low educational attainment and unstable and dense housing. Latinx and Pacific Islander community members are often employed in low-wage jobs, primarily in the poultry industry, which are deemed essential and do not allow them to work from home $[5,6]$.

For the past 5 years, the University of Arkansas for Medical Sciences (UAMS) has worked with Latinx and Pacific Islander community leaders and organizations to address health disparities and promote translational research. As the state's only academic health center, we leverage a community-engaged approach to build trust between academic health centers and community stakeholders [7-12]. These partnerships are funded by the Clinical and Translational Sciences Award (CTSA) at UAMS and the CDC's Racial and Ethnic Approaches to Community Health $(\mathrm{REACH})$ program. These partnerships have long-standing community advisory boards and conducted several projects and research initiatives together. Details about the partnership and the collaborative work of the community-academic partnership are published elsewhere [13].

The mission of the CTSA at UAMS is to develop new knowledge and novel approaches that will measurably address the complex health challenges of rural and underrepresented populations. Grant resources provide training and support for community-based participatory research, community engagement, plain language communications, and the expansion of research in special populations [14,15].

The REACH program has a three-pronged focus for advancing REACH: supporting culturally tailored interventions to address preventable health conditions; linking community and clinical efforts to increase access to health care and preventive care programs at the community 
level; and the implementation, evaluation, and dissemination of practice- and evidence-based strategies to reduce health disparities in chronic conditions [16].

In early 2020, community-engaged partnerships utilized their collaborative capacity to address COVID-19 disparities in the Latinx and Pacific Islander communities. No CDC or NIH funding was spent on COVID-19-specific activities outlined in this article. However, partners continue to leverage existing community-based capacity to engage the Pacific Islander and Latinx community while developing and executing a COVID-19 Response Strategy to Reduce Health Disparities. Funding was provided through the Arkansas Department of Health's distribution of CARES act funding [17]. This strategy is described below.

\section{A COVID-19 Strategy to Reduce Health Disparities for the Pacific Islander and Latinx communities in Northwest} Arkansas

Since March 2020, 18 key community partners have had weekly meetings, and there is often daily communication between partners. Partners collaboratively developed a COVID-19 Response Strategy to ensure coordinated effort for Latinx and Pacific Islander communities with four interrelated strategies: health education, testing, contact tracing, and supported quarantine/case management. Partners are listed in Table 1.

\section{Strategy 1: Health education and prevention}

Based on the recommendations from the CDC's July 2020 report, partners co-developed a communications strategy designed specifically for COVID-19. This strategy covers four areas: prevention, testing, quarantine, and follow-up care. Prevention communication focuses on behaviors and practices individuals can take to reduce their risk of infection, including when and how to wear a mask, hand washing, and how to stay connected with family and friends while maintaining an appropriate physical distance.

Communications about COVID-19 testing focuses on describing when and where people can be tested, provides bilingual videos for those places doing self-administered testing swabs, provides information about costs, and informs on safe behaviors while waiting for test results. The quarantine and isolation guidance focuses on criteria for when quarantine and self-isolation are appropriate and explains the available social services to support those efforts. Follow-up care covers symptom management and when and how to seek additional care if needed. Partners also developed targeted communications for high-risk community members, specifically addressing pregnancy, diabetes, mental health, and asthma. Small business and faith-based tool kits were created and have been distributed to more than 120 local small businesses within the Latinx and Pacific Islander communities. Communications primarily focus on nontraditional and unpaid media.

All communications are in English, Spanish, and Marshallese (the native language of most Pacific Islanders in Northwest Arkansas) and leverage local Latinx and Pacific Islander community leaders. The communications materials can be found at https://northwestcampus.uams.edu/ochrcovid/. An outline of communications tools developed as of November 30 is listed in Table 2. New communication tools are added frequently.

\section{Strategy 2: Testing}

The COVID-19 Strategy to Reduce Health Disparities for the Pacific Islander and Latinx communities is led by the Federally Qualified Health Center (FQHC), and employs the resources of
Table 1. Community partners and the sector partners represent

\begin{tabular}{|c|c|}
\hline Partner & Sector \\
\hline $\begin{array}{l}\text { Arkansas Children's Hospital } \\
\text { Northwest }\end{array}$ & Children's hospital \\
\hline $\begin{array}{l}\text { Arkansas Coalition of } \\
\text { Marshallese (ACOM) }\end{array}$ & Marshallese-focused nonprofit \\
\hline Arkansas Department of Health & State Health Department \\
\hline Arkansas Immigrant Defense & Immigrant-focused nonprofit \\
\hline $\begin{array}{l}\text { Arkansas United Community } \\
\text { Coalition }\end{array}$ & Diversity-focused nonprofit \\
\hline $\begin{array}{l}\text { Community Clinic of Northwest } \\
\text { Arkansas }\end{array}$ & Federally Qualified Health Center \\
\hline $\begin{array}{l}\text { Faith in Action Research and } \\
\text { Resources Alliance }\end{array}$ & Community nonprofit \\
\hline Hispanic Women's Organization & Latinx-focused nonprofit \\
\hline Kili Bikini Ejit & Marshallese-focused nonprofit \\
\hline $\begin{array}{l}\text { Marshallese Educational } \\
\text { Initiative (MEI) }\end{array}$ & Marshallese-focused nonprofit \\
\hline Mercy Health & $\begin{array}{l}\text { Three-hundred and fifty-five-bed } \\
\text { nonprofit hospital }\end{array}$ \\
\hline Northwest Arkansas Council & $\begin{array}{l}\text { Economic development organiza- } \\
\text { tion }\end{array}$ \\
\hline Northwest Health & $\begin{array}{l}\text { For-profit health system with five } \\
\text { hospitals in region }\end{array}$ \\
\hline $\begin{array}{l}\text { Republic of the Marshall Islands } \\
\text { Consulate }\end{array}$ & $\begin{array}{l}\text { Consulate office in Washington } \\
\text { County Arkansas }\end{array}$ \\
\hline Rooted NWA & Latinx-focused nonprofit \\
\hline UAMS & Academic Medical Center \\
\hline $\begin{array}{l}\text { Veterans Administration of the } \\
\text { Ozarks }\end{array}$ & Veterans health services in region \\
\hline $\begin{array}{l}\text { Washington Regional Medical } \\
\text { Center }\end{array}$ & $\begin{array}{l}\text { Four-hundred and twenty-five-bed } \\
\text { nonprofit hospital }\end{array}$ \\
\hline
\end{tabular}

Table 2. Types and estimated reach of COVID-19 communications materials

\begin{tabular}{ll}
\hline $\begin{array}{l}\text { Communications } \\
\text { medium }\end{array}$ & Number and estimated reach \\
\hline $\begin{array}{l}\text { Facebook live } \\
\text { sessions }\end{array}$ & $\begin{array}{l}\text { Twenty-nine videos developed and disseminated } \\
\text { via Facebook with an estimated average reach of } \\
21,000 \text { each video }\end{array}$ \\
\hline YouTube videos & $\begin{array}{l}\text { Twenty-one videos developed and distributed with } \\
\text { an average reach of } 7,120\end{array}$ \\
\hline Printed materials & $\begin{array}{l}\text { Forty-three printed educational documents } \\
\text { developed and distributed to more than 10,000 } \\
\text { people via food boxes, nonprofit organizations, } \\
\text { and testing centers }\end{array}$ \\
\hline Radio interviews & $\begin{array}{l}\text { Nine radio interviews with an estimated reach of } \\
12,000\end{array}$ \\
\hline $\begin{array}{l}\text { Faith-based tool } \\
\text { kit }\end{array}$ & $\begin{array}{l}\text { One tool kit in each of the } 3 \text { languages with an esti- } \\
\text { mated reach of } 50 \text { churches and 40,000 community } \\
\text { members }\end{array}$ \\
\hline $\begin{array}{l}\text { Small business } \\
\text { tool kit }\end{array}$ & $\begin{array}{l}\text { One tool kit in each of the } 3 \text { languages with an } \\
\text { estimated reach of } 120 \text { small businesses and } \\
150,000 \text { community members }\end{array}$ \\
\hline
\end{tabular}


UAMS, Arkansas Department of Health offices, and local healthcare providers for testing. Based on the CDC July 2020 report, testing primarily focuses on organizations and/or neighborhoods with a high number of cases so that partners can quickly target hot spots and reduce the spread. Targeted serial testing ensures rapid testing of all contacts of known or suspected COVID-19 cases. When a positive case is identified, all of their contacts are offered in-home testing. If the contact(s) prefer to not have testing at their home, they are directed to drive-through testing centers. For in-home testing, a nurse-led team of healthcare workers provide testing to contacts and all household members without contacts leaving their home. In addition, drive-through testing centers are distributed throughout two counties at local healthcare organizations and mobile testing teams conduct tests at churches, worksites, and housing complexes. Most importantly, all testing locations have bilingual staff. Community partners play an important role in helping identify the community-based location for mobile testing and encouraging community members to get tested at any of the testing locations.

\section{Strategy 3: A dedicated contact tracing center with bilingual workers}

The COVID-19 Strategy to Reduce Health Disparities for the Pacific Islander and Latinx communities focuses on establishing a bilingual contact tracing center in the region that fully integrates with the Arkansas Department of Health. The contact tracing center is staffed with bilingual contact tracing staff. The bilingual contact tracing center utilizes the same software, policies, and procedures as the Arkansas Department of Health and includes a designated process of identification and follow-up of all persons who may have come into contact with a person infected with COVID-19.

Since a positive test for COVID-19 is a mandatory reportable diagnosis to the Arkansas Department of Health, any new cases are reported, and those whose preferred language is Marshallese or Spanish are referred to the bilingual contact tracing center. Bilingual staff at the contact tracing center reach out to the case and determine direct contacts for the case during the period from 2 days before symptoms started until the case quarantined. The case is asked to inform all contacts that someone from the contact tracing center will be calling them. After the case alerts those contacts to expect a call, contact tracing staff will contact them to begin the screening process and advise quarantine. This quarantine applies to their households as well as any other direct contacts. This initial survey triggers a 14-day tracking period, which consists of daily communication with each contact under quarantine. All contact tracing data are entered into the Arkansas Department of Health software and uploaded to the department at the end of each day. All cases and contacts receive education about how to isolate (Strategy 1). Contacts are offered testing (Strategy 2). All cases and contacts who need assistance with food, housing, and medication work with a social worker and bilingual navigators to identify resources to meet those needs (Strategy 4).

\section{Strategy 4: Enhanced case management and supported quarantine}

A COVID-19 diagnosis often exacerbates the socioeconomic challenges that the Pacific Islander and Latinx populations face in Northwest Arkansas. Bilingual social workers, nurses, and community health navigators make up the enhanced case management team. It is critical to provide support services for both cases and contacts as they self-quarantine. Needed support includes essentials like food and medications, coordination with worksites, and coordination with community behavioral health services. Standard contact tracing encourages contacts to stay home and maintain distance from others until 14 days after their last exposure. The enhanced case management process elevates this with follow-up communication with the person who has COVID-19 and contacts to follow all quarantine guidelines. The enhanced case management also discusses their health and inquires about new symptoms. The staff provides resources, education, information, and connection with health care and community-based support organizations. They arrange for both food deliveries and prescription drug refills, if needed, to facilitate the contacts' ability to remain at home. The nonprofit organizations listed in Table 1 have funding and actively take part in ensuring cases and contacts have the support they need.

\section{Conclusion}

The COVID-19 Strategy to Reduce Health Disparities for the Pacific Islander and Latinx communities in Northwest Arkansas demonstrates how community-based participatory research and programmatic networks funded by NIH and the CDC can be quickly leveraged to address COVID-19, which has disproportionately affected Latinx and Pacific Islander community members. This example shows the importance of building and sustaining community-based research and programmatic networks. The regional collaborative in Northwest Arkansas plans to leverage their network in the future to ensure Pacific Islander and Latinx communities have the opportunity to participate in vaccine studies and the distribution of COVID-19 vaccines.

Acknowledgments. These efforts are supported in part by CARES Act funding (PAM) and the Blue and You Foundation of Arkansas (PAM). The communitybased participatory research team was provided by a Translational Research Institute grant (\#1U54TR001629-01A1) from the National Center for Advancing Translational Sciences of the National Institutes of Health (PAM) and the Racial and Ethnic Approaches to Community Health (REACH) grant (\#1NU58DP006595-01) from the Centers for Disease Control and Prevention (PAM). We thank the numerous community partners who have worked on these efforts. These partners are listed in Table 1 . We specifically thank the Northwest Arkansas Council and Community Clinic for their leadership in the effort.

Disclosures. The authors have no conflicts of interest to declare.

\section{References}

1. Stokes EK, Zambrano LD, Anderson KN, et al. Coronavirus Disease 2019 Case Surveillance - United States, January 22-May 30, 2020. MMWR Morbidity and Mortality Weekly Report 2020; 69(24): 759-765. doi: 10.15585/mmwr.mm6924e2

2. Servick K. 'Huge hole' in COVID-19 testing data makes it harder to study racial disparities [Internet], 2020. (https://www.sciencemag.org/news/ 2020/07/huge-hole-covid-19-testing-data-makes-it-harder-study-racialdisparities).

3. Thebault R, Tran A, Williams V. The coronavirus is infecting and killing black Americans at an alarmingly high rate. The Washington Post [Internet], 2020. (https://www.washingtonpost.com/nation/2020/04/ 07/coronavirus-is-infecting-killing-black-americans-an-alarmingly-high-ratepost-analysis-shows/?arc404=true) 
4. Smith J, Medalia C. Health Insurance Coverage in the United States: 2014; 2015.

5. Centers for Disease Control and Prevention. Summary Report CDC AR-3 Field Team COVID-19 among Hispanic and Marshallese communities in Benton and Washington Counties, Arkansas. Atlanta, GA: Centers for Disease Control and Prevention; 2020.

6. Harris P, Jones N. We the People: Pacific Islanders in the United States Census 2000 Special Reports. Washington, DC: US Census Bureau; 2005.

7. Wallerstein NB, Duran B. Using community-based participatory research to address health disparities. Health Promotion Practice 2006; 7(3): 312-323. doi: $10.1177 / 1524839906289376$

8. Wallerstein N, Duran B. Community-based participatory research contributions to intervention research: the intersection of science and practice to improve health equity. American Journal of Public Health 2010; 100(Suppl 1): S40-S46. doi: 10.2105/AJPH.2009.184036

9. Israel BA, Coombe CM, Cheezum RR, et al. Community-based participatory research: a capacity-building approach for policy advocacy aimed at eliminating health disparities. American Journal of Public Health 2010; 100(11): 2094-2102. doi: 10.2105/ajph.2009.170506

10. Minkler M. Ethical challenges for the "outside" researcher in communitybased participatory research. Health Education \& Behavior 2004; 31(6): 684-697. doi: 10.1177/1090198104269566
11. Minkler M, Wallerstein $\mathbf{N}$ (eds.). Community-Based Participartory Research for Health: From Process to Outcomes. Hoboken, NJ: Jossey-Bass Publishers; 2008.

12. Minkler M. Linking science and policy through community-based participatory research to study and address health disparities. American Journal of Public Health 2010; 100(Suppl 1): S81-S87. doi: 10.2105/ajph.2009.165720

13. McElfish P, Kohler P, Smith C, et al. Community-driven research agenda to reduce health disparities. Clinical and Translational Science 2015; 8(6): 690-695. doi: 10.1111/cts.12350

14. Huff-Davis A, Cornell CE, McElfish P, Kim Yeary KH. Strategies to facilitate equitable resource sharing in community-engaged research. Progress in Community Health Partnerships 2018; 12(2): 173-177. doi: 10.1353/cpr. 2018.0037

15. Stewart MK, Spencer N, Huff Davis A, Hart C, Boateng B. Developing and piloting a community scientist academy to engage communities and patients in research. Journal of Clinical and Translational Science 2018; 2(2): 73-78. doi: $10.1017 /$ cts.2018.20

16. Centers for Disease Control and Prevention. REACH: CDC's Racial and Ethnic Approaches to Community Health Program. (https://www.cdc.gov/ chronicdisease/resources/publications/factsheets/reach.htm)

17. COVID-19 CARES Act. Arkansas Department of Finance and Administration; 2020. (https://www.dfa.arkansas.gov/administrative-services/ covid-19-cares-act) 